\title{
Risk of depressive disorder following disasters and military deployment: systematic review with meta-analysis
}

J. P. Bonde, N. Utzon-Frank, M. Bertelsen, M. Borritz, N. H. Eller, M. Nordentoft,

K. Olesen, N. H. Rod and R. Rugulies

\section{Background}

Numerous studies describe the occurrence of post-traumatic stress disorder following disasters, but less is known about the risk of major depression.

\section{Aims}

To review the risk of depressive disorder in people surviving disasters and in soldiers returning from military deployment.

\section{Method}

A systematic literature search combined with reference screening identified 23 controlled epidemiological studies. We used random effects models to compute pooled odds ratios (ORS).

\section{Results}

The average OR was significantly elevated following all types of exposures: natural disaster $\mathrm{OR}=2.28(95 \% \mathrm{Cl} 1.30-3.98)$, technological disaster $\mathrm{OR}=1.44(95 \% \mathrm{Cl} 1.21-1.70)$, terrorist acts $\mathrm{OR}=1.80(95 \% \mathrm{Cl} 1.38-2.34)$ and military combat $\mathrm{OR}=1.60(95 \% \mathrm{Cl} 1.09-2.35)$. In a subset of ten high-quality studies OR was 1.41 (95\% Cl 1.06-1.87).

\section{Conclusions}

Disasters and combat experience substantially increase the risk of depression. Whether psychological trauma per se or bereavement is on the causal path is unresolved.

\section{Declaration of interest}

None.

\section{Copyright and usage}

(c) The Royal College of Psychiatrists 2016.
Disasters may in addition to immediate death and physical injury have an impact on mental health. ${ }^{1}$ Although there is consensus that disasters may cause transient or persistent post-traumatic stress disorder (PTSD) among those who survive them, ${ }^{2-4}$ less is known about the relation between disasters and the risk of developing depressive disorder. There may be an overlap between mass catastrophic events as disasters and exposures addressed in the extensive literature on major life events and risk of depression, but the latter is dominated by studies of bereavement, assault, serious disease and economic loss or crime accusations. ${ }^{5}$ Since there is strong evidence that major life events substantially increase the risk of depression, ${ }^{5}$ it seems plausible that the experience of psychological trauma in relation to natural or technological disasters, acts of terrorism and armed conflicts might be an important risk factor for depression. In 1991 Rubonis \& Bickman reviewed 52 studies addressing psychological impairment following exposure to disasters and pointed to several methodological limitations of research linking disaster exposure with mental health outcomes. ${ }^{6}$ These included inadequate description of study populations, lack of representative or random sampling procedures and of appropriate reference groups, lack of pre-disaster data on psychiatric morbidity and limited attention to disaster characteristics and temporal factors. Moreover, psychopathological outcomes were vaguely defined in most studies and only six studies provided valid data for a meta-analytic evaluation of mood disorders. Norris et al described risk factors, health outcomes and impairment in 160 samples of disaster survivors including more than 60000 individuals, but - although informative - this paper did not include controlled risk estimates for specific mental disorders. ${ }^{7}$ Since these reviews were published several studies with improved epidemiological designs have been conducted, but an updated systematic review of evidence linking disasters with risk of development of major depression has to the best of our knowledge not been published.
Our objective was to examine the risk of developing depressive disorder among adult individuals surviving mass disasters such as natural or technological catastrophes and armed conflicts including terroristic acts. We also addressed military deployment in order to include exposure encountered during professional service and because large studies with appropriate data have become available. Moreover, we specifically aimed to address the risk of depression according to type of disaster and population characteristics.

\section{Method}

The review was conducted and reported according to the Preferred Reporting Items for Systematic Reviews and Meta-analyses (PRISMA) statement. We searched original peer-reviewed journal articles in English that provided data on the occurrence of major depression or depressive symptoms following exposure to disasters or military deployment. Studies had to provide at least one estimate of the relative risk or an equivalent measure in the exposed group compared with an appropriate reference group at specified time periods after the disaster or end of military deployment. Articles were identified through a systematic search in PubMed, PsycINFO and EMBASE from 1 January 1980 through 30 June 2014. We combined medical subject headings and generic terms for the exposure (such as disaster, hurricane, earthquake, combat, deployed) and outcome (depression, PTSD, psychopathological) and focused the search by requesting controlled studies and reporting of risk estimates for the association between disaster or military deployment and depression. The search yielded 995 publications in PubMed, 88 in PsycINFO and 334 in EMBASE. A full documentation of the search is given in the online data supplement. Two authors (J.P.B. and N.U.-F.) sifted the titles and read the abstracts and, if necessary, the full publication 
to determine eligibility of the study according to the following inclusion and exclusion criteria. Included studies comprised a population of adults exposed to a natural disaster, technological disaster, armed conflict, terrorist act or military deployment. Studies addressing children and adolescents exposed to such events were excluded. Major life events such as loss of close relatives, serious disease or injury, breakdown of relationships, severe loss of property, bankruptcy, unemployment and other social calamities did not qualify: for example, a study on depression in battle-injured soldiers was excluded. ${ }^{8}$ Moreover, only studies explicitly addressing people exposed directly (personal threat) or indirectly (witnesses) to a catastrophic event were included: for instance, a US study of psychiatric morbidity among women in combat supporting military service was not included, because the participants were not directly or indirectly exposed to such events. ${ }^{9}$ Other inclusion criteria were:

(a) explicit recording of current depression or probable depression by international diagnostic criteria according to self-report or clinical interview;

(b) reporting of risk estimates for depression in relation to a catastrophic event by reference to an appropriate internal and/or external reference group;

(c) reporting of confidence limits of risk estimates or of data that enabled the authors to compute measures.

Articles were not included in the review if they compared continuous summary statistics of depressive symptoms across exposure groups without providing data on proportions fulfilling specified diagnostic criteria. Many papers provided several risk estimates. We included estimates of risk related to exposure to a catastrophic event per se rather than risk related to loss of job, property or relatives. For example, in a study of mental health outcomes among residents of New York City after the 11 September terrorist attack on the World Trade Center, we selected risk related to distance of residence from the Center rather than risk related to loss of relatives during the attack. ${ }^{10}$ Furthermore, we selected objective indicators of exposure to psychological trauma rather than subjective recall of exposure (online Table DS1). After applying all inclusion and exclusion criteria and excluding duplicates, 15 of the initial 1417 publications remained eligible (online Fig. DS1). Screening of bibliographies of the retrieved literature resulted in 8 additional eligible papers, yielding a final database of 23 original publications. ${ }^{10-32}$ No attempt was made to retrieve unpublished studies.

\section{Quality assessment}

\section{Reporting}

Each publication was evaluated for completeness of reporting by considering the following study characteristics: ${ }^{33}$ study design, sampling procedure, inclusion and exclusion criteria, response rate, assessment of exposure, ascertainment of outcome and statistical analysis. We evaluated whether the essential information was provided for each of these study characteristics and assigned a value of 1 if the criterion was fulfilled and 0 if not. Giving equal weight to each of the seven characteristics, we considered completeness of reporting as sufficient if at least six out of the seven characteristics were reported.

\section{Confounding}

Known determinants of major depression include gender, age, social class, family history of depression, earlier psychiatric morbidity and bereavement. ${ }^{34}$ If the risk estimates of interest were not adjusted for effects of the most prevalent covariates (gender, age and social class) by design or analysis, we considered confounding to be an unresolved issue unless it was otherwise documented that the distribution of risk factors was balanced across exposure groups. Pre-existing depression and previous trauma may modify associations between exposure and outcome, but are hardly confounding associations because catastrophic exposure is expected to occur at random.

\section{Bias}

Observational studies addressing risk factors for depressive disorder may be biased by several factors. First, differential recall of exposure may inflate the relative risk if data on exposure are collected by selfreport after the depressive disorder was diagnosed. This applies to the studies where exposure was not defined by objective criteria related to the event but by self-reported exposure. Second, bias that tends to cause an overestimation of risks can also arise from selection if exposed people with symptoms or disease are more likely to participate in the study than non-exposed people with similar symptoms. We considered selection bias to be likely if the participation rate in the reference group was less than two-thirds of the participation in the exposure group, unless evaluation of the non-response rendered it probable that risk estimates were unaffected by differential participation. If recall bias, selection bias or both were present according to these criteria, a study was classified as probably being biased towards too high risk estimates (inflationary bias; Table DS1). Third, non-differential misclassification of exposure to a catastrophic event can cause bias towards the null when assessment is based on crude measures of exposure. For instance, military deployment is not equivalent to combat exposure, and combat exposure can imply very different levels of threat. Fourth, since the prevalence of post-disaster psychiatric disorder declines with time after the event, ${ }^{10}$ risk estimates are expected to be skewed towards lower values in studies in which data collection took place several years after the initial exposure. Each study was evaluated with respect to the likelihood of inflationary and deflationary bias respectively, based on the above-mentioned criteria.

\section{Statistical analysis}

To obtain a pooled risk estimate across studies we first averaged risk estimates within a study if several relevant risk estimates were provided - for example, when risk was evaluated at several time points after the catastrophic event, or if risk estimates were provided separately for men and women or for several types or levels of exposure. We fitted a fixed effect model to compute an average estimate within a study (Stata version 12, METAN procedure). In the next step we computed a pooled risk estimate across all 23 studies by weighing the odds ratio (OR) or equivalent (relative risk or hazard ratios) by the inverse variance using random effects models, because the true risk, if any, is likely to differ across studies. Heterogeneity was assessed by the $I^{2}$ statistic. $^{35}$ In a subsequent step we evaluated the risk according to type of disaster and according to time elapsed from the event until outcome ascertainment. When time from disaster or end of military deployment to examination was reported as a range we used the median value. If a study did not provide risk estimates but reported data on population size and the prevalence of the outcome in exposed and comparison groups, we computed the odds ratio with $95 \%$ confidence intervals. In sensitivity analyses we excluded studies with potential confounding, bias causing inflation of risk estimates or missing information on two or more of the seven study characteristics that we evaluated. In the subset of higher-quality studies we again computed the weighted odds 
ratio for depressive disorder. Potential publication bias was addressed by funnel plots displaying study size by risk estimate and by evaluation of asymmetry using Egger's test. ${ }^{35}$

\section{Results}

We identified 11 prospective cohort studies, 1 case-control study and 11 cross-sectional studies, in total 23 original studies that reported the risk of depression or depressive symptoms following exposure to a disaster or after military deployment (Table DS1). Completeness of reporting with respect to description of design, sampling procedures, populations, response rates, exposure assessment, outcome ascertainment and statistical analyses was high. In 5 studies, information was considered complete and in 10 studies information was missing on only one characteristic. Response rates of $70 \%$ or more were reported in only 11 studies $(46 \%)$, but most studies with low participation rates provided comprehensive analysis of the non-response. Inflation of risk estimates because of biased recall of exposure or selective inclusion of participants with disorder in the exposure groups was likely in 7 studies. In 8 studies, underestimation of risk was likely because of crude exposure assessment - for instance by inclusion of residents who were marginally affected by a disaster. Finally, 8 studies did not adjust or control for potentially confounding effects of gender, age or social class.

Table 1 summarises study characteristics according to type of catastrophic event. Reference groups were either drawn from appropriate population samples or constituted by less or indirectly exposed individuals. Diagnostic ascertainment was based on clinical interviews according to DSM-III or DSM-IV criteria in the majority of studies, ${ }^{2}$ but some surveys addressing large population samples used self-reports (Table DS1). The pooled odds ratio for depressive disorder following a disaster or military deployment across all 23 studies with 37 risk estimates was 2.08 (95\% CI 1.53-2.81), with large variation between studies $\left(I^{2}=98.7 \%, P<0.001\right.$; Fig. 1$)$. In the subset of 10 high-quality studies (19 risk estimates), i.e. studies with complete reporting on at least 6 of 7 study characteristics and less likelihood of confounding or inflationary bias, the pooled OR was lower: $\mathrm{OR}=1.41,95 \%$ CI 1.06-1.87 (Fig. 2). The average risk estimate for the 5 high-quality studies addressing technological or terroristic disasters was $1.47 \quad(95 \%$ CI $1.30-1.65)$ without significant heterogeneity $\left(I^{2}=25.5 \%, P=0.21\right)$.

The pooled OR for depression in the cohort studies was 1.88 (95\% CI 1.23-2.88), slightly lower than in cross-sectional studies $(\mathrm{OR}=2.57,95 \% \mathrm{CI} 1.81-3.66)$. Australian veterans with former deployment in the Vietnam war experienced by far the highest risk of depression (Fig. 1). ${ }^{17}$ Omitting this study with an outlying risk estimate produced an overall OR of 1.82 (95\% CI $1.50-$ 2.22). The pooled risk of depression was significantly elevated following exposure to all types of disasters (natural disaster, technological disaster and terrorist acts) and after military deployment (Fig. 1). However, military deployment per se without combat exposure was not related to increased risk (pooled $\mathrm{OR}=1.93,95 \%$ CI $0.78-4.76$ ). The risk did not decline with time elapsed since exposure and remained markedly elevated for years after the event among citizens surviving atrocities in former Yugoslavia, ${ }^{23}$ and to a lesser extent among Cambodian refugees who escaped to the USA. ${ }^{28}$ Among soldiers, combat during deployment was a significant risk factor $(\mathrm{OR}=1.60,95 \% \mathrm{CI}$ 1.09-2.35). ${ }^{18,21,26,36}$ The average risk estimates in studies using ascertainment of the diagnosis by clinical interview (14 risk estimates) were not different from the majority of studies where the outcome relied on questionnaire self-reports (26 risk estimates), namely $\mathrm{OR}=1.90$ (95\% CI 1.51-2.40) for the former and $\mathrm{OR}=2.25(95 \%$ CI $1.48-3.44)$ for the latter.

The average weighted risk for depression varied by study size. It was lowest in 6 studies enrolling more than 10000 participants $(\mathrm{OR}=1.25$, 95\% CI 0.88-1.79), higher in 9 studies with 1000 10000 participants $(\mathrm{OR}=1.98,95 \%$ CI $1.32-2.96)$ and highest in 8 studies with fewer than 1000 participants $(\mathrm{OR}=3.30,95 \%$ CI 1.38-7.93). A funnel plot demonstrating the relationship between precision and magnitude of the risk estimate indicates a tendency that large studies systematically report risks of smaller magnitude (online Fig. DS2(a)). The funnel plot for the nine cohort studies of higher quality is provided in Fig. DS2(b) and shows less heterogeneity.

\section{Discussion}

Through a systematic search of the literature we identified 23 controlled epidemiological studies that addressed the risk of depressive disorder among people surviving disasters and in soldiers after military deployment. The risk of depressive disorder was moderately increased following exposure to all types of catastrophic events except military deployment without combat exposure. Risk was also elevated in the subset of studies with prospective data collection and in the subset of higher-quality studies that were less prone to bias. This review is to the best of our knowledge the first systematic evaluation of controlled studies to scrutinise the effect of disaster and military deployment exposure on risk of depressive disorder, which - unlike PTSD is defined independently of the cause.

Table 1 summary characteristics of 23 observational studies with 37 estimates for risk of depression following exposure to a disaster or military deployment with and without combat exposure

\begin{tabular}{|c|c|c|c|c|c|c|c|c|c|}
\hline & \multirow{2}{*}{$\begin{array}{l}\text { No. of } \\
\text { studies }\end{array}$} & \multirow{2}{*}{$\begin{array}{l}\text { No. of risk } \\
\text { estimates }^{\text {a }}\end{array}$} & \multicolumn{3}{|c|}{ Study size (participants), $n$} & \multirow{2}{*}{$\begin{array}{l}\text { Diagnosis by } \\
\text { interview/all }\end{array}$} & \multicolumn{3}{|c|}{ Time since event, months } \\
\hline & & & $<1000$ & $1000-10000$ & $>10000$ & & $<12$ & $12-24$ & $>24$ \\
\hline \multicolumn{10}{|l|}{ Disasters } \\
\hline Natural & 6 & 7 & 5 & 2 & 0 & $4 / 7$ & 4 & 3 & 0 \\
\hline Terrorism & 7 & 13 & 4 & 6 & 3 & $3 / 13$ & 8 & 0 & 5 \\
\hline Technological $\left.\right|^{\mathrm{b}}$ & 2 & 4 & 2 & 2 & 0 & $0 / 4$ & 1 & 2 & 1 \\
\hline All & 15 & 24 & 11 & 10 & 3 & $7 / 24$ & 13 & 5 & 6 \\
\hline \multicolumn{10}{|l|}{ Military } \\
\hline Deployment & 7 & 9 & 1 & 3 & 5 & $2 / 9$ & 4 & 2 & 3 \\
\hline Combat & 3 & 4 & 0 & 0 & 4 & $2 / 4$ & 3 & 1 & 0 \\
\hline All & $8^{c}$ & 13 & 1 & 3 & 9 & $4 / 13$ & 7 & 3 & 3 \\
\hline
\end{tabular}




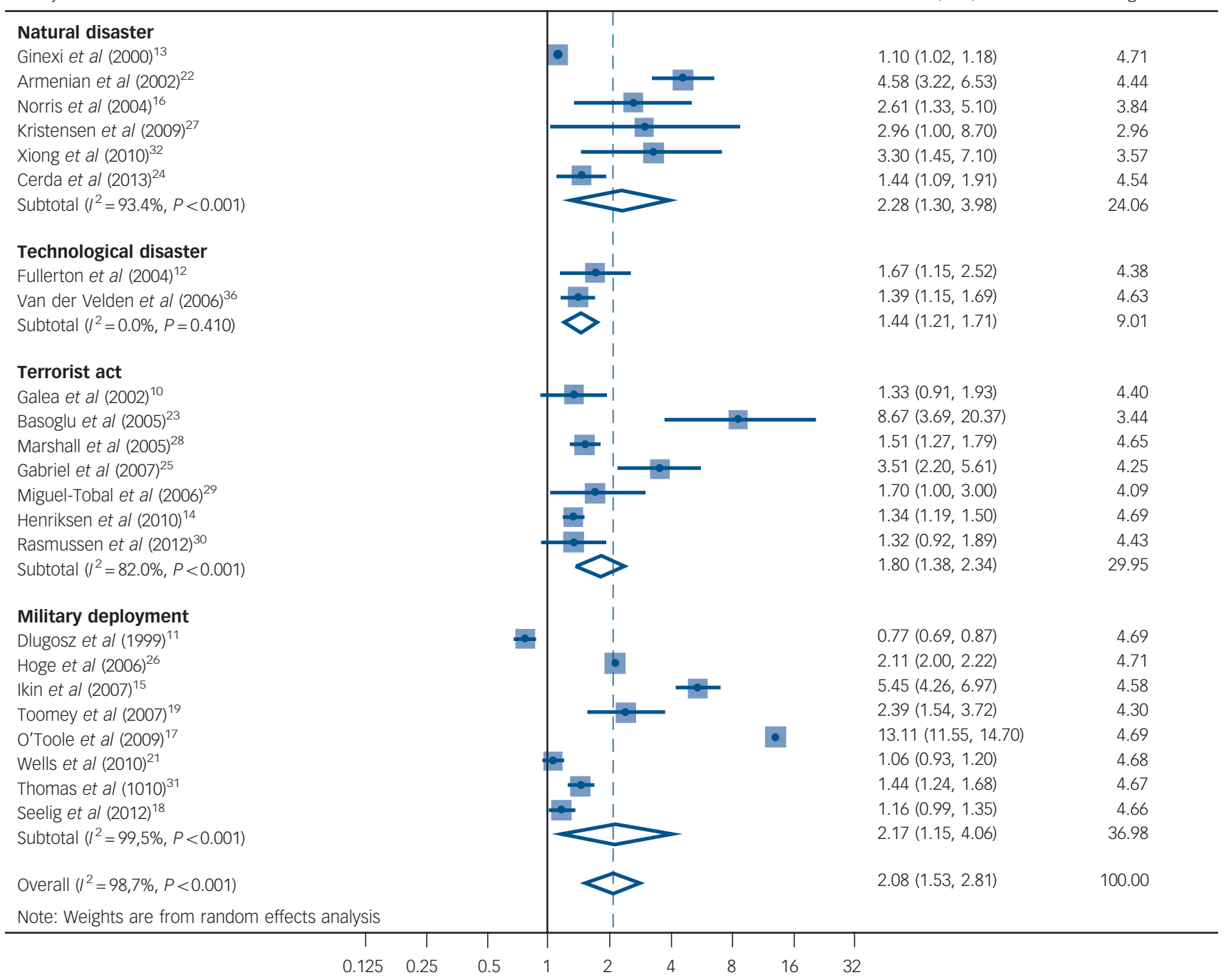

Fig. 1 Forest plot showing odds ratios with $95 \%$ confidence intervals for depressive disorder following disaster or military deployment (random effects models categorised by type of exposure). ES, effect size.

\section{Heterogeneity of risk across studies}

The risk of depression varied substantially across studies from a relative risk slightly above 1 in people indirectly exposed to the attack on the World Trade Center in New York City, ${ }^{14}$ to a relative risk above 10 in a small group of randomly selected Australian Vietnam veterans examined many years after the war. ${ }^{17}$ It is noteworthy, however, that with one exception all 23 risk estimates were above unity, indicating that heterogeneity primarily is about magnitude of effect. Besides chance and publication bias several explanations for the heterogeneity of risk across studies can be hypothesised, although the summary data available for this review were too limited to allow for detailed analysis and statistical testing of these hypotheses. First, the prevalence of high-intensity exposure to psychological trauma may be limited in studies enrolling very large numbers of participants, which may cause misclassification of exposure and underestimation of the true risk. ${ }^{14,21}$ This hypothesis is supported by the observation that the risk was lower in the large studies enrolling more than 10000 individuals. Second, the impact of repeated psychological trauma and exposure to threats during longer time periods, for example among soldiers in combat, people entrapped in war zones or displaced people after natural disasters, may be different and perhaps more persistent than effects of single events such as mass transportation accidents. Unfortunately, the number of studies is too limited to allow analysis of this issue. Third, the timing of outcome ascertainment relative to the time of exposure may be a determinant of the incidence of depressive disorder because of the time-varying course of this disorder. ${ }^{34}$ As expected the occurrence of depression declined with time after the disaster or end of deployment in four studies with repeated follow-up periods, ${ }^{14,28,31,36}$ but not in two other studies, ${ }^{12,19}$ one of which addressed depressive disorder in disaster workers involved in an aircraft crash. ${ }^{12}$ Fourth, it has been suggested that human responsibility in terrorist acts and assaults may have a larger impact than natural disasters, ${ }^{6}$ but the data presented in this paper do not point to this mechanism. Fifth, methodological issues and study design may also explain differences in magnitude of effects. Studies using self-report to identify cases of depressive disorder are likely to report higher disorder occurrence than studies that perform rigorous outcome ascertainment by clinical interview. ${ }^{37}$ If effects of severe psychological trauma are highly specific, 


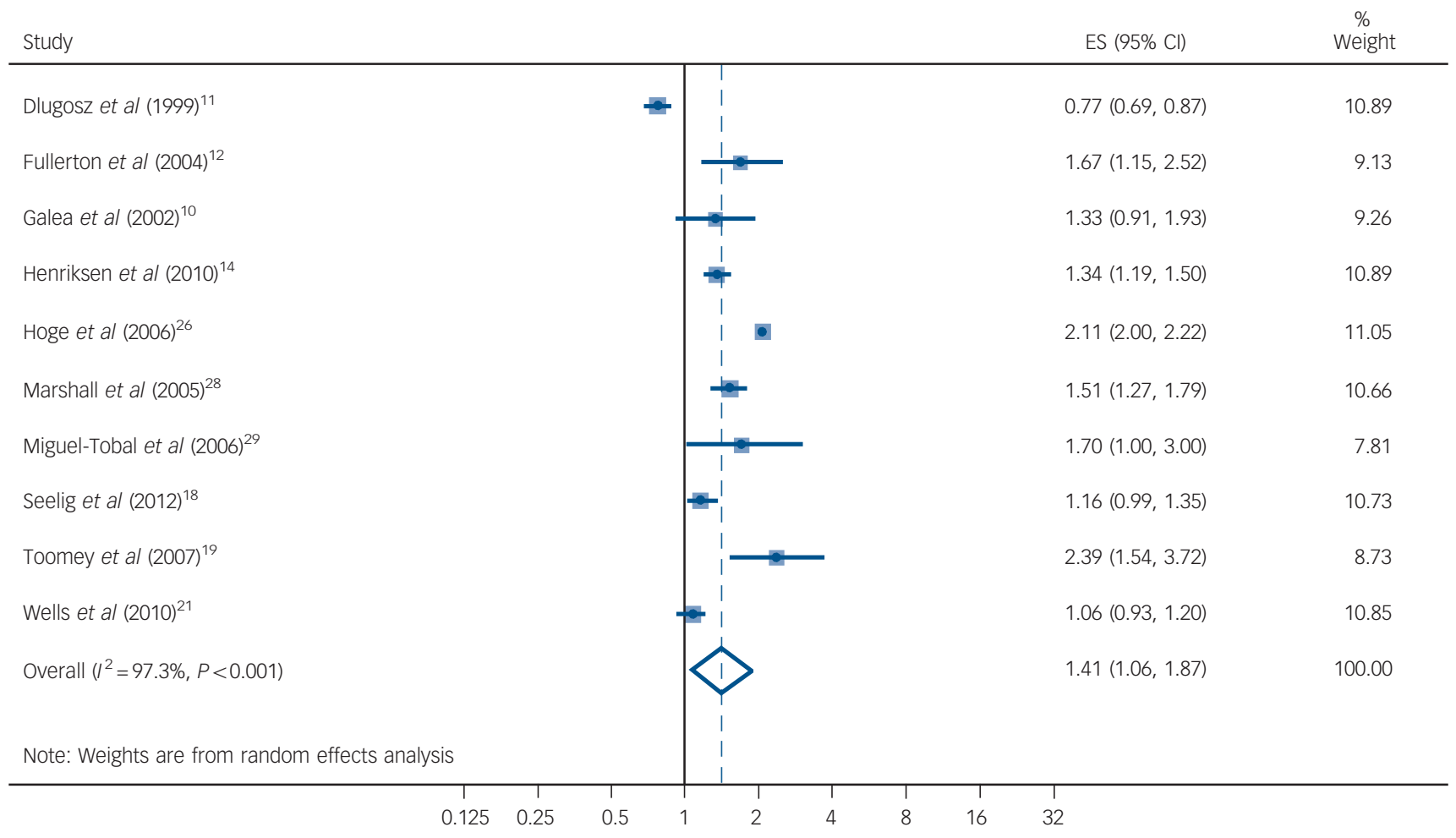

Fig. 2 Forest plot showing odds ratios with $95 \%$ confidence limits of depressive disorder following disaster or military deployment: higher-quality studies with complete reporting and lower risk of bias and confounding (random effects model). ES, effect size.

misclassification of outcome by use of less reliable diagnostic tools would most probably result in underestimation of the relative risk. Considering the high comorbidity of all type of mood, anxiety and substance use disorders that are described in relation to disasters, ${ }^{16}$ this is, however, hardly the case.

\section{Strengths and limitations}

The meta-analysis revealed a consistent association between exposure to disasters or military deployment and occurrence of depression in spite of large methodological differences and inherent heterogeneity between studies. Two studies provided evidence of exposure-response relations, ${ }^{21,22}$ and four out of six studies with repeated follow-up assessments indicated a declining risk with increasing time after the catastrophic event. ${ }^{28,30,31,36}$ This is to be expected if post-traumatic depressive disorder has a course similar to the one described for PTSD. ${ }^{16}$ Biased recall of exposure is not an issue in the majority of studies using objective and independent criteria of exposure. Even in the cross-sectional studies, confounding by pre-existing disease seems unlikely in those studies where the catastrophic event struck randomly, such as in an aircraft crash or subway bombing. However, in soldiers, screening programmes and experience during earlier deployment may cause selection of more healthy and less susceptible individuals.

The funnel plot showing a systematic overrepresentation of large studies among those with small risk estimates may be an indication of publication bias causing inflated risk estimates. We believe, however, that a more likely explanation is misclassification of exposure with attenuated effects in the large studies with enrolment of thousands of participants who were not all heavily exposed to trauma. In addition, depression was not the primary focus of any of the studies, which also diminishes the risk of publication bias. We did not include reports and other manuscripts not published in peer-reviewed journals, because it is hard to identify this literature in a transparent and systematic way. This may also contribute to inflation of overall risk estimates, but nevertheless the risk estimates based on the subset of high-quality studies should be considered reliable.

\section{Mechanisms}

A cross-sectional interview study of the prevalence of PTSD and major depression following the 11 September terrorist attacks in New York City found an increased prevalence of both conditions among residents living near the World Trade Center. However, whereas current PTSD was related to direct exposure to the attacks, major depression was related to a loss of a relative, property or job as a result of the event. ${ }^{10}$ These data indicate that some or all of the risk of depression that has been attributed to a disaster may be caused by personal loss resulting from the event rather than the experience of severe acute psychological trauma per se. Additional data are needed to corroborate or refute this hypothesis.

Two studies consistently reported that combat during deployment was a risk factor for major depression. ${ }^{18,21}$ It is less clear whether military deployment without any specified combat or other traumatic exposure poses a risk of subsequent depressive disorder. Studies of Gulf War veterans and of US armed forces deployed in Iraq and Afghanistan did not reveal higher risks of depression, ${ }^{11,18,21}$ whereas studies of Australian Vietnam veterans and deployed National Guard soldiers did report higher risks of depression. ${ }^{17,31}$ Whether depression and other mental disorders that occur among soldiers after returning home is caused by traumatic combat experience during deployment or by psychological distress related to the process of returning to civil 
life is disputed, ${ }^{38}$ and cannot be resolved by the studies included in this review.

\section{Study implications}

The results of our study are compatible with findings in longitudinal studies of depression trajectories following experience of such traumatic events as myocardial infarction and the World Trade Center attacks. ${ }^{39,40}$ The latter study identified five distinct trajectories of depression (no depression, mild delayed depression, recovery, severe delayed depression and chronic severe depression), and ongoing socioeconomic adversity was associated with a worse course of depressive symptoms. ${ }^{40}$ Although these longitudinal studies provide insight into the heterogeneous time course of symptoms in groups exposed to catastrophic events, they are less informative as regards causal links owing to the lack of reference groups. Our results suggest that not only PTSD but also depression should be considered to be a consequence of traumatic exposure. This may have consequences for compensation claims, for example in lawsuits against those responsible for the disasters or in claims at workers' compensation boards. Moreover, the general practitioner should be aware that the experience of a disaster may be a forerunner of depression.

\section{Concluding remarks}

A series of controlled epidemiological studies provide evidence that a wide range of catastrophic events including natural disasters, mass-scale accidents, terrorist acts and atrocities in armed conflicts and military combat increase the risk of depressive disorder. However, data are too limited to resolve issues relating to dose-response, timing and the time course following the event.

J. P. Bonde, DMSC, N. Utzon-Frank, MD, Department of Occupational and Environmental Medicine, Bispebjerg University Hospital; M. Bertelsen, PhD, Danish Veteran Centre, Copenhagen; M. Borritz, PhD, N. H. Eller, DMSC, Department of Occupational and Environmental Medicine, Bispebjerg University Hospital; M. Nordentoft DMSC. Psychiatric Centre Bispebjerg Bispebjerg University

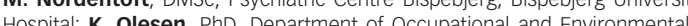
Medicine, Bispebjerg University Hospital, and Department of Public Health, University of Copenhagen; N. H. Rod, DMSc, Department of Public Health, University of Copenhagen; R. Rugulies, PhD, Department of Public Health, University of Copenhagen, National Research Centre for the Working Environment, and Department of Psychology, University of Copenhagen, Denmark

Correspondence: Professor Jens Peter Bonde, Department of Occupational and Environmental Medicine, Bispebjerg Hospital, Bispebjerg Bakke 232400 Copenhagen NV, Denmark. Email: jpb@bbh.regionh.dk

First received 26 Jan 2014, final revision 23 May 2015, accepted 28 May 2015

\section{Funding}

The study was supported by a grant from the Danish Work Environment Research Fund (NR 20130000299/3).

\section{Acknowledgements}

We are grateful for comments on an earlier version of the manuscript provided by Sir simon Wessely, Geert Smid and Sigurd Mikkelsen.

\section{References}

1 Norris FH, Friedman MJ, Watson PJ, Byrne CM, Diaz E, Kaniasty K. 60,000 disaster victims speak: Part I. An empirical review of the empirical literature, 1981-2001. Psychiatry 2002; 65: 207-39.

2 American Psychiatric Association. Diagnostic and Statistical Manual of Mental Disorders (4th edn) (DSM-IV). APA, 1994.
3 Andrews B, Brewin CR, Philpott R, Stewart L. Delayed-onset posttraumatic stress disorder: a systematic review of the evidence. Am J Psychiatry 2007; 164: 1319-26.

4 Utzon-Frank N, Breinegaard N, Bertelsen M, Borritz M, Eller NH, Nordentoft $\mathrm{M}$, et al. Occurrence of delayed-onset post-traumatic stress disorder: a systematic review and meta-analysis of prospective studies. Scand J Work Environ Health 2014; 40: 215-29.

5 Kessler RC. The effects of stressful life events on depression. Annu Rev Psychol 1997; 48: 191-214.

6 Rubonis AV, Bickman L. Psychological impairment in the wake of disaster: the disaster-psychopathology relationship. Psychol Bull 1991; 109: 384-99.

7 Norris FH, Friedman MJ, Watson PJ. 60,000 disaster victims speak: Part II. Summary and implications of the disaster mental health research. Psychiatry 2002; 65: 240-60.

8 Grieger TA, Cozza SJ, Ursano RJ, Hoge C, Martinez PE, Engel CC, et al. Posttraumatic stress disorder and depression in battle-injured soldiers. Am J Psychiatry 2006; 163: 1777-83.

9 Lindstrom KE, Smith TC, Wells TS, Wang LZ, Smith B, Reed RJ, et al. The mental health of U.S. military women in combat support occupations. J Womens Health (Larchmt) 2006; 15: 162-72.

10 Galea S, Ahern J, Resnick H, Kilpatrick D, Bucuvalas M, Gold J, et al. Psychological sequelae of the September 11 terrorist attacks in New York City. N Engl J Med 2002; 346: 982-7.

11 Dlugosz L, Hocter WJ, Kaiser KS, Knoke JD, Heller JM, Hamid NA, et al. Risk factors for mental disorder hospitalization after the Persian Gulf War: U.S. Armed Forces, June 1, 1991-September 30, 1993. J Clin Epidemiol 1999; 52: 1267-78.

12 Fullerton CS, Ursano RJ, Wang L. Acute stress disorder, posttraumatic stress disorder, and depression in disaster or rescue workers. Am J Psychiatry 2004; 161: 1370-6.

13 Ginexi EM, Weihs K, Simmens SJ, Hoyt DR. Natural disaster and depression: a prospective investigation of reactions to the 1993 midwest floods. Am J Community Psychol 2000; 28: 495-518.

14 Henriksen CA, Bolton JM, Sareen J. The psychological impact of terrorist attacks: examining a dose-response relationship between exposure to 9/11 and Axis I mental disorders. Depress Anxiety 2010; 27: 993-1000.

15 Ikin JF, Sim MR, McKenzie DP, Horsley KW, Wilson EJ, Moore MR, et al. Anxiety, post-traumatic stress disorder and depression in Korean War veterans 50 years after the war. Br J Psychiatry 2007; 190: 475-83.

16 Norris FH, Murphy AD, Baker CK, Perilla JL. Postdisaster PTSD over four waves of a panel study of Mexico's 1999 flood. J Trauma Stress 2004; 17 283-92.

17 O'Toole BI, Catts SV, Outram S, Pierse KR, Cockburn J. The physical and mental health of Australian Vietnam veterans 3 decades after the war and its relation to military service, combat, and post-traumatic stress disorder. Am J Epidemiol 2009; 170: 318-30.

18 Seelig AD, Jacobson IG, Smith B, Hooper TI, Gackstetter GD, Ryan MA, et al. Prospective evaluation of mental health and deployment experience among women in the US military. Am J Epidemiol 2012; 176: 135-45.

19 Toomey R, Kang HK, Karlinsky J, Baker DG, Vasterling JJ, Alpern R, et al. Mental health of US Gulf War veterans 10 years after the war. Br J Psychiatry 2007; 190: 385-93.

20 Van den Berg B, Grievink L, van der Velden PG, Yzermans CJ, Stellato RK, Lebret $E$, et al. Risk factors for physical symptoms after a disaster: a longitudinal study. Psychol Med 2008; 38: 499-510.

21 Wells TS, LeardMann CA, Fortuna SO, Smith B, Smith TC, Ryan MA et al. A prospective study of depression following combat deployment in support of the wars in Iraq and Afghanistan. Am J Public Health 2010; 100: 90-9.

22 Armenian HK, Morikawa M, Melkonian AK, Hovanesian A, Akiskal K, Akiskal HS. Risk factors for depression in the survivors of the 1988 earthquake in Armenia. J Urban Health 2002; 79: 373-82.

23 Basoglu M, Livanou M, Crnobaric C, Franciskovic T, Suljic E, Duric D, et al. Psychiatric and cognitive effects of war in former Yugoslavia: association of lack of redress for trauma and posttraumatic stress reactions. JAMA 2005; 294: $580-90$.

24 Cerda M, Paczkowski M, Galea S, Nemethy K, Pean C, Desvarieux M. Psychopathology in the aftermath of the Haiti earthquake: a populationbased study of posttraumatic stress disorder and major depression. Depress Anxiety 2013; 30: 413-24.

25 Gabriel R, Ferrando L, Corton ES, Mingote C, Garcia-Camba E, Liria AF, et al. Psychopathological consequences after a terrorist attack: an epidemiological study among victims, the general population, and police officers. Eur Psychiatry 2007; 22: 339-46. 
26 Hoge CW, Auchterlonie JL, Milliken CS. Mental health problems, use of mental health services, and attrition from military service after returning from deployment to Iraq or Afghanistan. JAMA 2006; 295: 1023-32.

27 Kristensen $\mathrm{P}$, Weisaeth $\mathrm{L}$, Heir T. Psychiatric disorders among disaster bereaved: an interview study of individuals directly or not directly exposed to the 2004 tsunami. Depress Anxiety 2009; 26: 1127-33.

28 Marshall GN, Schell TL, Elliott MN, Berthold SM, Chun CA. Mental health of Cambodian refugees 2 decades after resettlement in the United States. JAMA 2005; 294: 571-9.

29 Miguel-Tobal JJ, Cano-Vindel A, Gonzalez-Ordi H, Iruarrizaga I, Rudenstine S, Vlahov D, et al. PTSD and depression after the Madrid March 11 train bombings. J Trauma Stress 2006; 19: 69-80.

30 Rasmussen A, Crager M, Baser RE, Chu T, Gany F. Onset of posttraumatic stress disorder and major depression among refugees and voluntary migrants to the United States. J Trauma Stress 2012; 25: 705-12.

31 Thomas JL, Wilk JE, Riviere LA, McGurk D, Castro CA, Hoge CW. Prevalence of mental health problems and functional impairment among active componen and National Guard soldiers 3 and 12 months following combat in Iraq. Arch Gen Psychiatry 2010; 67: 614-23.

32 Xiong X, Harville EW, Mattison DR, Elkind-Hirsch K, Pridjian G, Buekens P. Hurricane Katrina experience and the risk of post-traumatic stress disorder and depression among pregnant women. Am J Disaster Med 2010; 5: 181-7.

33 Bonde JP, Jorgensen KT, Bonzini M, Palmer KT. Miscarriage and occupational activity: a systematic review and meta-analysis regarding shift work, working hours, lifting, standing, and physical workload. Scand J Work Environ Health 2013; 39: 325-34.

34 Wittchen HU, Knauper B, Kessler RC. Lifetime risk of depression. $\mathrm{Br} \mathrm{J}$ Psychiatry 1994; 165 (suppl 26): 16-22.

35 Sterne JAC. Meta-analysis in Stata: an updated collection from the Stata Journal. Stata Press, 2009

36 Van der Velden PG, Grievink L, Kleber RJ, Drogendijk AN, Roskam AJ, Marcelissen FG, et al. Post-disaster mental health problems and the utilization of mental health services: a four-year longitudinal comparative study. Adm Policy Ment Health 2006; 33: 279-88.

37 Kolstad HA, Hansen AM, Kaergaard A, Thomsen JF, Kaerlev L, Mikkelsen S, et al. Job strain and the risk of depression: is reporting biased? Am J Epidemiol 2011; 173: 94-102.

38 Jones M, Sundin J, Goodwin L, Hull L, Fear NT, Wessely S, et al. What explains post-traumatic stress disorder (PTSD) in UK service personnel: deployment or something else? Psychol Med 2013; 43: 1703-12.

39 Kaptein $\mathrm{KI}$, de Jonge $\mathrm{P}$, van den Brink $\mathrm{RH}$, Korf J. Course of depressive symptoms after myocardial infarction and cardiac prognosis: a latent class analysis. Psychosom Med 2006; 68: 662-8.

40 Nandi A, Tracy M, Beard JR, Vlahov D, Galea S. Patterns and predictors of trajectories of depression after an urban disaster. Ann Epidemiol 2009; 19 : 761-70 